\title{
Cultivation Path of Medical Students' Tacit Professional Quality in the Age of "Wise Information Technology of 120" Based on the Framework of Collaboration between Medicine and Education
}

\author{
Tingting Chen, Wangting Li, Xianchun Wen \\ Qiqihar Medical University \\ Qiqihar, Heilongjiang Province, China
}

\author{
Han Lin \\ First Affiliated Hospital \\ Qiqihar Medical University \\ Qiqihar, Heilongjiang Province, China
}

\begin{abstract}
This work studied the new requirements of the tacit professional quality on medical students in the era of "Wise Information Technology of 120", and aimed to explore ways and means to cultivate qualified medical students. The research group used literature review, research visits and other methods to study. The innovation point is that under the framework of collaboration between medicine and education, doctors and medical students are the research objects respectively. As a result, based on the rules and characteristics of their respective tacit quality formation, the long-term educational mechanism of establishing political-school-enterprise linkage can be summarized and a new cultivation path of diversified education can be expanded.
\end{abstract}

Keywords-"Wise Information Technology of 120"; Collaboration between medicine and education; Medical students; Tacit professional quality; Path exploration

\section{INTRODUCTION}

The Fifth Plenary Session of the 18th CPC Central Committee put forward the grand goal of "promoting the construction of healthy China" [1], which further promoted the construction of "Wise Information Technology of 120" project. In the era of "Wise Information Technology of 120", the medical industry, like other industries, is bound to be greatly influenced by big data, artificial intelligence and the Internet of things. In this context, the era of "Wise Information Technology of 120" puts forward higher requirements for the tacit professional qualities of medical students. At the same time, the comprehensive quality education with the cultivation of medical students' professional quality as the core is an inevitable requirement for the transformation of modern medical models and the internationalization of medical education, which is in line with the direction of the national medical and health system reform and the people's demand for

(1) Heilongjiang Province Education Science "13th Five-Year Plan" 2017 Record Project (No. GBD1317152).

(2) Qiqihar Medical University Education Research Project (No. QYJY20170108).

(3) Innovation and Entrepreneurship Training Program of College Students in Heilongjiang University in 2018 (No. 201811230017). medical and health services [2-3].

At present, domestic and foreign scholars have basically reached a consensus on the connotation of doctors' professional quality. Xu Jinyang and others believe that [4]: "The professional quality of medical students is to adapt to the basic knowledge and professional knowledge, clinical skills, humanities, teamwork, professionalism, humanity quality and scientific spirit." However, these invisible tacit professional qualities are difficult to be identified through simple and external methods, or cultivated through a single book, therefore, they are easy to be neglected. Since the 1980s, the strong trend of medical education reform in Western countries has been to improve the professionalism of doctors by strengthening medical humanities education. In 1978, the British Higher Education Commission recommended that sociology, psychology, ethics, social medicine, behavior medicine and medical law should be added into compulsory courses in medical schools, so that the humanities would be integrated into medical education. In 1995, most medical schools in the United States opened humanities courses. China also pays more and more attention to the cultivation of medical students' humanistic quality, but this kind of cultivation mostly stays at the school level and has not formed the long-term cultivation mechanism from medical students to doctors. This work was to explore the long-term cultivation path of tacit professional qualities before and after the transformation from medical students to doctors based on the framework of collaboration between medicine and education.

\section{The Tacit Professional Qualities that Medical STUdENTS SHOULD POSSESS IN THE ERA OF "WISE INFORMATION TECHNOLOGY OF 120"}

Tacit professional qualities mainly refer to invisible ability and quality such as professional ethics, professional consciousness and professional attitude. Tacit professional qualities can lay a follow-up path for students to develop their career, having a deeper and more lasting impact on medical students' occupation [5]. Medical students, as practitioners of 
the future medical industry, can only become qualified practitioners in the future if they have a high degree of tacit professionalism. After consulting literature, this research group summarizes five aspects of tacit professional quality that should be possessed or improved for medical students in the era of "Wise Information Technology of 120".

\section{A. In the era of "Wise Information Technology of 120", more} emphasis is placed on the innovative consciousness and innovative ability of medical students

Technological innovation has always accompanied the development of medicine: in 1895, Rontgen discovered X-ray, which caused a revolution in medical diagnosis. Humans can observe the inside of the human body without incision; In 1928, penicillin was introduced; In 1953, DNA double helix was discovered, which revealed the secret of life; In 1954, the first kidney transplant was successful, creating the era of organ transplantation; In 1972, the first CT was born; In 1987, the French doctor completed the first invasive surgery; In 2001, the human genome work sketch was published; Now, mankind has entered the ear of "Wise Information Technology of 120", precision medicine, targeted therapy, big data, molecular imaging and molecular pathology. Medical development is nothing but innovation. Therefore, innovation should be the quality and ability of medical students supposed to possess.

From another perspective, the era of "Wise Information Technology of 120 " that is being built will inevitably lead to subversive changes in the medical industry. Artificial intelligence doctors can "precisely" characterize patients so that they can improve the accuracy of many important disease predictions. With the clinical application of artificial intelligence doctors, do human doctors feel the "rice bowl" crisis? With the promotion of 5G technology, telemedicine is developing rapidly. China has successfully completed the first human implantation of brain pacemaker for Parkinson's disease based on 5G technology. Such development puts higher demands on the level of medical skills of human doctors. In summary, in the future development of medical innovation, medical students should have innovative consciousness and innovative ability, so that they will not be eliminated by social development.

\section{B. In the era of "Wise Information Technology of 120", more} emphasis is placed on the transferable skills of medical students.

"Wise Information Technology of 120" will generally integrate into four main bodies, including cloud storage and cloud computing, big data technology, Internet of Things and mobile technology. "Wise Information Technology of 120" is integrated and developed on the basis of these four. In such technological development, the requirements on talents for mastering interdisciplinary and interdisciplinary knowledge and skills are proposed in addition to the professional knowledge and skills. For example: the ability to collect and organize information and the ability to analyze and process data. This requires future medical talents to have more transferable skills and to be able to master interdisciplinary and cross-disciplinary knowledge and skills in a timely manner. A single professional has been unable to meet future requirements. It is reported that the demand for talents engaged in medical and health informationization in China has risen sharply and the gap is very large.

\section{In the era of "Wise Information Technology of 120", more emphasis is placed on the lifelong learning ability of medical students}

Now is the era of the Big Bang, in which the knowledge is updated quickly, and the technology is updated faster, requiring health care practitioners to master new technologies and new skills in a timely manner. In addition, some recruiting units have higher requirements on the qualifications of practitioners, and medical staff also needs to keep learning on the path of promotion of their professional titles. Therefore, lifelong learning ability is a very important ability for future medical practitioners.

\section{In the era of "Wise Information Technology of 120", more emphasis is placed on the communication and problem-solving ability of medical students}

At present, the contradiction between doctors and patients has become a hot issue of social concern. Exploring the root causes of doctor-patient contradictions, there are many factors in communication between doctors and patients. If there is any disagreement or misunderstanding in the communication between doctors and patients, contradictions will inevitably occur in the subsequent medical treatment. Therefore, how the doctor can communicate effectively with the patients and their families at all levels that can produce good results is the basic guarantee for doctors to successfully complete the treatment.

In addition, the medical industry has certain risks from diagnosis, medication to surgery, and the complexity of individual diseases, the limitations of doctor-patient cognition, and the inexperience of practitioners in the medical industry will bring risks to doctors. This requires medical practitioner to have the ability to solve problems in a responsive manner. The ability to solve problems based on rich practical experience is an important indicator of a qualified medical student.

\section{E. In the era of "Wise Information Technology of 120", more emphasis is placed on the sense of responsibility and the rule of law of medical students.}

The sense of responsibility refers to the awareness, feelings and beliefs of individuals to take responsibility of themselves and others, as well as the conscious attitude of complying with norms, taking responsibility and fulfilling their obligations. The profession of doctors is about the life and health of patients, and it is about the quality of life in many families. Therefore, this profession emphasizes responsibility more. At the same time, responsibility is also the basic method for medical practitioners to avoid making low-level mistakes such as giving wrong medicine to children that happened in Yixing, Jiangsu and the bottom line for medical practitioners to adhere to. Therefore, the sense of responsibility is one of the important contents of the tacit professional quality cultivation for medical students.

In recent years, vicious incidents such as beating medical staff, hiring criminals to block hospitals, forcing doctors to kneel down and even killing doctors have occurred frequently, which have become a sore point of the society. To solve these 
problems, it is still necessary to act in accordance with the law and go through legal procedures. Therefore, medical students should know the law, understand the law and use it. Only in this way can they follow the law and use legal weapons to defend their legitimate rights and interests when problems arise.

\section{Research on the Cultivation Path of Medical STUDENTS' TACIT PROFESSIONAL QUALITY BASED ON THE FRAMEWORK OF COLLABORATION BETWEEN MEDICINE AND EDUCATION}

In 2014, the promotion meeting of deepening the cultivation reform of medical talents put forward the concept and measures of "collaboration between medicine and education". In the same year, the Ministry of Education and the Ministry of Health jointly issued the Opinions on the Collaboration between Medicine and Education to Deepen the Cultivation of Medical Talents, and China launched a new round of medical education reform. This round of new education aimed to build a "5+3" (5-year clinical medical education +3 years of clinical medical master's degree graduate education or 3 years of resident doctors standardized training) as the main training system for clinical medical personnel, which ran the cultivation of clinical medical students through the whole process of medical college, hospital, medical industry and society. Under the framework of collaboration between medicine and education, the research group proposed to explore the path of cultivating medical students' tacit professional quality from the following four aspects.

\section{A. Giving full play to government functions and guiding to establish a humanistic education cooperation mechanism between medical schools and standardized training bases}

" $5+3$ " has become the basic mode to cultivate medical students in China and the inevitable course for every medical student who wants to become a doctor. In the eight years, humanities education in crucial in addition to the cultivation of professional knowledge and clinical practice ability. The eight years are an important period to shape the professional ideal, professional planning and professional values of medical students. Therefore, medical humanities education should form an eight-year system of education, which requires more scientific and close cooperation between medical schools and standardized training bases. At present, the cooperation between medical schools and standardized training bases is loose, which requires administrative means such as overall planning, policy guidance and political regulation in the coordination and cooperation, so as to improve the establishment of a long-term cooperation mechanism for humanities education between medical schools and standardized training bases.

\section{B. From the perspective of top-level design, medical schools should pay attention to the integration of humanistic quality education in talent training programs}

Due to its strong professionalism and large amount of professional knowledge, medical schools have formed a mindset of "emphasizing majors but neglecting humanities" in the undergraduate education stage. Therefore, in order to change the concept of medical students, it is necessary to pay attention to humanities general education at the very start. Qiqihar Medical University is an ordinary higher medical university, whose orientation is to "keep a foothold in Heilongjiang, face the whole country, serve the grassroots, and cultivate applied medical and health talents." In the process of cultivating talents, the university puts forward the "three orientations" talent training mode, that is, the humanistic quality education oriented by professional emotions, the professional quality training guided by the practical ability to practice and the development of physical and mental quality guided by social adaptation [6]. Guided by this, the university clearly states in the general higher education training program that it is necessary to adhere to the principle of strengthening moral education and cultivating people, correctly handling the relationship between general education and professional education, humanities education and science education. According to the "three orientations" talent training goal, the university published the "three-oriented" series of textbooks, and opened a series of courses such as Introduction to the Growth of Medical Students, Medical Humanities and Doctors and Patients. Through the integration of multiple disciplines and the integration of medical and humanistic disciplines, the cultivation of medical professional knowledge and humanistic quality, professional ethics and communication skills is organically integrated to promoting the cultivation of medical students' tacit professional quality.

\section{From the perspective of curriculum construction, medical schools should construct a personalized curriculum system of medical humanities education}

The particularity of the medical profession puts forward higher and more targeted requirements on the professional attitudes, professional beliefs, professional ethics and other humanistic qualities of medical students. Therefore, individualized medical humanities education should be emphasized in the humanities curriculum.

In the theoretical courses, Qiqihar Medical University opens a total of 96 individualized elective courses such as humanities, public art, and social sciences for the whole students, and has nearly 200 online elective courses. In the construction of practical curriculum system, the university adheres to the "three early" education policy, that is, early exposure to the society, early exposure to the clinic and early exposure to the scientific research. It opens many personalized practical courses, such as "going to rural areas three times" social practice and studying scientific research with professors as research assistants. In addition, the "Sunshine Morning Exercise", the annual team competition and the Tai Chi competition have become the fine tradition of the university, in which students have also cultivated humanistic qualities such as teamwork, innovation and perseverance.

For the students majoring in pathology, Qiqihar Medical University effectively utilizes the only clinical pathology diagnosis center in Qiqihar to establish an innovative education mode integrating theory and practice, so as to improve the employment adaptability and the ability to serve the community of pathology graduates. 
quality for medical students should be established under the

D. From the perspective of collaboration, expanding diversified educational subject is conducive to establishing a long-term cultivation atmosphere for medical students' tacit professional quality

Whether the medical profession, the educational circle or the society has realized the necessity and importance of the tacit professional quality cultivation. However, as far as the current education model is concerned, the main body of education is still medical schools, and the object of education only emphasizes medical students, which is incompatible with the current era of rapid development and diversified social trends. From the perspective of collaboration, the educational object is not only medical students, but also doctors, and the education subject is not only medical schools, but also extends to hospitals. At the same time, it is necessary to pay attention to the guidance and edification of media public opinion on medical students' career, values and other aspects of humanistic quality, and play the positive energy communication role of party organizations, league organizations, and other formal organizations at all levels to create a good society, build a good atmosphere and strengthen all-round humanistic education for medical students.

\section{SUMMARY}

Cultivating the tacit professional quality for medical students is a slow process, which is impossible to be completed overnight. It needs continuous input, and the results may be difficult to measure with data. The ultimate goal of cultivation should be to form a harmonious social atmosphere between doctors and patients, and doctors feel stronger professional happiness and better professional experience. Based on the above characteristics, the cultivation of tacit professional framework of integrating the collaboration of the government, universities and hospitals to establish a long-term, continuous and targeted cultivation mode. In the process of cultivating, it is necessary to pay attention to the combination of theory and practice, the absorption of diversified cultivation subjects and the content of people-oriented education, so as to finally achieve the practical results of conceptualization, theorization, and practical action.

\section{REFERENCES}

[1] National Health and Family Planning Commission of the People's Republic of China. The 13th Five-Year Plan for Healthy China Construction is Open to the Public[OL]. 2015. http://www.nhfpc.gov.cn/guihuaxxs/s3586s/201512/8383c591091e465b b1db6c728b107e76.shtml.

[2] Zhang Meng, Sun Fuchuan. Internationalization of Higher Education and Quality Education for Medical Students[J]. Chinese Medical Ethics, 2006, 19(5): 59-60.

[3] Hu Guanglai. Thoughts on Strengthening the Humanities Quality Education of Medical Students Under the Background of New Medical Reform[J]. Journal of Nanjing Medical University, 2011(6): 460-462.

[4] Xu Jinyang, Liu Canzhen et al. An Empirical Research on the Development of Medical Students' Professional Quality - Taking Shantou University Medical College as an Example[j]. Medical Education Research and Practice, 2017, 25(2): 189-191

[5] Zhao Xuefeng, Wang Chunhong. Research on the Effective Methods of the Cultivation of Tacit Professional Quality of Medical Students[J]. China Health Industry, 2017 (24): 88-89

[6] Liu Jicheng, Zhang Xiaojie, Yun Changhai et al. Exploration and Practice of the Reform of the Three-oriented Talent Training Mode Aiming at the Future Development for Medical Students[J]. China Higher Medical Education, 2014, (4): 1-2 